\title{
Cross-Sectional Study of Burnout among a Group of Egyptian Oncologists at Ain Shams University
}

\author{
Ramy R. Ghali ${ }^{1}$, Dina N. K. Boulos ${ }^{2}$, Mohamed Alorabi ${ }^{1}$ \\ 1 Clinical Oncology Department, Faculty of Medicine, Ain Shams University, Cairo, Egypt; ${ }^{2}$ \\ Community, Environmental and Occupational Medicine Department, Faculty of Medicine, Ain Shams \\ University, Cairo, Egypt
}

Background: Oncologists are at risk of developing burn out syndrome due to many stressors they may face. Aim: To determine the level of burnout in a cohort of clinical oncologists working in an Egyptian university hospital. Methods: Fifty-two clinical oncologists were invited to participate in the study. Burnout was assessed using the Arabic version of Maslach Burnout Inventory Human Services Survey (MBI-HSS).

Results: The response rate was $90 \%$ (47/52). The majority $(70 \%)$ of responders were young oncologists and $62 \%$ had $>10$ years experience in the oncology field. Females represented 52\% of them and $62 \%$ were married. The MBI-HSS scores indicated that $72 \%$ of participants had burnout on the emotional exhaustion (EE) scale, $49 \%$ on the depersonalization (DP) scale and $38 \%$ on the personal accomplishment (PA) scale. A significantly lower PA score was associated with female gender, being single, viewing vacation time as insufficient, and an experience duration $\leq 10$ years in oncology ( $\mathrm{p}=0.01,0.01,0.03$, and 0.02 ; respectively). The preference not to choose again oncology as a career was also associated with significantly lower PA score and higher EE score ( $\mathrm{p}=0.02$ and 0.001 ; respectively).

Conclusion: The surveyed oncologists experienced high burnout. Larger studies are needed in order to assess the burden of the problem and to develop evidence-based interventions to reduce it.

Corresponding Author: Ramy Ghali, MD; Clinical Oncology Department, Faculty of Medicine, Ain Shams University, Cairo, Egypt; E-mail: ramyghali@hotmail.com

Keywords: Burnout, Oncologists, Egypt

Submitted: 8-April-2018, Revised: 17-May-18, Accepted: 21-May-18, Published online: 19-November-2018

\section{INTRODUCTION}

Burnout syndrome (BS) is characterized by emotional exhaustion (EE), depersonalization (DP) and reduced personal accomplishment (PA) ${ }^{1}$. At the personal level of health care professionals, it is known to have a detrimental effect on the quality of life and may be associated with a higher risk of suicidal thinking among them ${ }^{2}$. Furthermore, burnout may contribute to a decrease in the quality of care provided and an increase in medical errors. Absenteeism, less empathy and changing career are other consequences of burnout ${ }^{3,4}$.

Although rewarding, caring for cancer patients is demanding and stressful ${ }^{5}$. Oncologists work long hours, supervise the administration of chemotherapy and are continuously exposed to death and suffering ${ }^{6,7}$. Burnout and compassion fatigue are common among oncologists as found in many studies from around the world ${ }^{8-10}$.

Insufficient vacation time, patients' unrealistic expectations, frequent losses and ethical issues are among the factors that my increase burnout and psychological morbidity among oncologists ${ }^{8}$.

Burnout has not been studied before among Egyptian oncologists. This study was conducted to determine the prevalence of burnout and to examine factors that may contribute to it in a group of Egyptian clinical oncologists working at Ain Shams University.

\section{METHODS}

\section{Study population}

This cross-sectional study was conducted on fifty-two volunteering oncologists working at Ain Shams Faculty of Medicine-Clinical Oncology Department, after getting approval from the institutional ethical committee.

\section{Data collection}

Study participants filled a self-administrated anonymous questionnaire consisting of two parts.

The first part covered age, gender, marital status, number/age of children, current professional rank, studying for a medical degree, years of experience in oncology field, working hours per week, number of patients examined per day, night shifts, practicing regular physical activity/hobby, vacation time, effect of working in oncology field on family and social life, possibility of choosing oncology as a career again. These questions aimed to assess socio-demographic and occupational background.

The second part of the questionnaire included the Arabic version of the Maslach Burnout Inventory 
Human Services Survey (MBI-HSS), which was used to assess burnout after obtaining the permission of the developers ${ }^{11}$. The MBI-HSS is well known as the leading and most commonly used measure of burnout and is validated by extensive research that has been conducted since its initial publication ${ }^{1}$. It includes 22-items divided into three subscales: 9 items to measure emotional exhaustion (EE), 5 to measure depersonalization (DP) and 8 to measure personal accomplishment (PA). For each item, a 7-point Likert scale was used to assess response. Higher scores on the EE and DP scales and lower scores on the PA indicate higher burnout level. Scores indicating burnout were classified as high on the basis of cut-off points recommended by the developer of the MBI scale ${ }^{11}$. Burnout was defined as high levels of emotional exhaustion, high levels of depersonalization or low levels of personal accomplishment.

Participants were asked to complete the questionnaire within one week away from stressful conditions.

\section{Statistical analysis}

The Statistical Package for the Social Sciences (SPSS) for Windows (version 19, IBM Corp., New York, USA) was used for data analysis. Descriptive statistics were calculated for the socio-demographic and occupational characteristics and for the three aspects of burnout. Student's $t$-test, was used to test differences in the MBI subscale scores according to the socio-demographic and job characteristics. All statistical tests were two-tailed, with a significance level of 0.05 .

\section{RESULTS}

The vast majority (47/52, 90.4\%) of invited oncologists completed the questionnaire. Table 1 illustrates the socio-demographic characteristics of participants. The majority of participants were $<40$ years of age, females, married and having children. A minority of them had regular physical activity, practiced regular hobby and considered vacation sufficient.

Job characteristics of participating oncologists are illustrated in table 2. The majority (70.2\%) of participants stated that they would choose oncology again as a career if they had the chance to do. The other $29.8 \%$ preferred to choose another specialty. Regarding the impact of practicing oncology on social life and family, most $(68.1 \%)$ of participants believed that it has a mixed positive and negative impact and only $6.4 \%$ believed that it has a negative impact.

The average scores of the MBI subscales and categorization of participants according to the score are shown in table 3.

In bivariate analysis (table 4), the only variable associated with significantly higher EE and DP scores and lower PA score was the oncologists' preference not to choose oncology as a specialty again if they had the chance to do so. There was significant association between higher PA scores with male gender, being married, considering vacation sufficient and $>10$ years experience.

Table 1: Socio-demographic characteristics of the study participants

\begin{tabular}{|c|c|c|}
\hline & No. & $\%$ \\
\hline \multicolumn{3}{|l|}{ Age } \\
\hline$<40$ years & 33 & 70.2 \\
\hline$>40$ years & 14 & 29.8 \\
\hline \multicolumn{3}{|l|}{ Sex } \\
\hline Male & 21 & 44.7 \\
\hline Female & 26 & 55.3 \\
\hline \multicolumn{3}{|l|}{ Marital status } \\
\hline Single & 18 & 38.3 \\
\hline Married & 29 & 61.7 \\
\hline \multicolumn{3}{|l|}{ Having children } \\
\hline Yes & 26 & 55.3 \\
\hline No & 21 & 44.7 \\
\hline \multicolumn{3}{|c|}{ Regular physical activity } \\
\hline Yes & 11 & 23.4 \\
\hline No & 36 & 76.6 \\
\hline \multicolumn{3}{|l|}{ Regular hobby } \\
\hline Yes & 11 & 23.4 \\
\hline No & 36 & 76.6 \\
\hline \multicolumn{3}{|c|}{ Consider vacation sufficient } \\
\hline Yes & 12 & 25.5 \\
\hline No & 35 & 74.5 \\
\hline
\end{tabular}

Table 2: Job characteristics of the study participants

\begin{tabular}{lll}
\hline & No. & \% \\
\hline Professional rank & & \\
\hline Resident & 10 & 21.3 \\
\hline Assistant Lecturer & 14 & 29.8 \\
\hline Lecturer & 9 & 19.1 \\
\hline Associate Professor & 5 & 10.6 \\
\hline Professor & 9 & 19.1 \\
\hline
\end{tabular}

\begin{tabular}{lll}
\hline Years of experience in oncology field & & \\
\hline$\leq 10$ years & 29 & 61.7 \\
\hline$>10$ years & 18 & 38.3 \\
\hline Currently studying for a medical degree & & \\
\hline Yes & 34 & 72.3 \\
\hline No & 13 & 27.7 \\
\hline Working hours per week & & \\
\hline$\leq 48$ hours & 26 & 55.3 \\
\hline$>48$ hours & 21 & 44.7
\end{tabular}

\begin{tabular}{lll}
\hline Number of patients examined per day & & \\
\hline$\leq 15$ patients & 23 & 48.9 \\
\hline$>15$ patients & 24 & 51.1 \\
\hline Working night shifts & & \\
\hline Yes & 14 & 29.8 \\
\hline No & 33 & 70.2 \\
\hline
\end{tabular}


Table3. MBI subscales score and interpretation

\begin{tabular}{lllll}
\hline Subscale & Mean (SD) & \multicolumn{2}{l}{ Burnout level (n [\%]) } \\
\cline { 3 - 5 } & & Low & Moderate & High \\
\hline Emotional exhaustion (EE) & $33.9(13.1)$ & $2(4.3)$ & $11(23.4)$ & $34(72.3)$ \\
\hline Depersonalization (DP) & $13.1(6.2)$ & $7(14.9)$ & $17(36.2)$ & $23(48.9)$ \\
\hline Personal accomplishment (PA) & $32.4(6.4)$ & $8(17)$ & $21(44.7)$ & $18(38.3)$ \\
\hline
\end{tabular}

Table 4: Mean MBI subscale scores according to participants' socio-demographic and job characteristics

\begin{tabular}{|c|c|c|c|c|c|c|c|c|c|}
\hline \multirow{2}{*}{$\begin{array}{l}\text { Sociodemographic } \\
\text { characteristics }\end{array}$} & \multicolumn{3}{|c|}{ Emotional exhaustion } & \multicolumn{3}{|c|}{ Depersonalization } & \multicolumn{3}{|c|}{ Personal accomplishment } \\
\hline & Mean (SD) & $\mathbf{t}$ & p value & Mean (SD) & $\mathbf{t}$ & p value & Mean (SD) & $\mathbf{t}$ & p value \\
\hline \multicolumn{10}{|l|}{ Age groups } \\
\hline$\leq 40$ years & $34.3(9.5)$ & \multirow[t]{2}{*}{0.25} & \multirow[t]{2}{*}{0.79} & $13.8(4.8)$ & \multirow[t]{2}{*}{1.15} & \multirow[t]{2}{*}{0.25} & $31.5(6.9)$ & \multirow[t]{2}{*}{1.47} & \multirow[t]{2}{*}{0.14} \\
\hline$>40$ years & $33.2(19.5)$ & & & $11.5(8.6)$ & & & $34.5(4.5)$ & & \\
\hline \multicolumn{10}{|l|}{ Gender } \\
\hline Male & $33.3(15.8)$ & \multirow[t]{2}{*}{0.27} & \multirow[t]{2}{*}{0.78} & $15.1(11.6)$ & \multirow[t]{2}{*}{1.96} & \multirow[t]{2}{*}{0.056} & $35(3.3)$ & \multirow[t]{2}{*}{2.7} & \multirow[t]{2}{*}{0.01} \\
\hline Female & $34.4(10.5)$ & & & $11.6(5.7)$ & & & $30.2(7.5)$ & & \\
\hline \multicolumn{10}{|l|}{ Marital status } \\
\hline Single & $36.3(10.4)$ & \multirow[t]{2}{*}{0.97} & \multirow[t]{2}{*}{0.33} & $14(4.7)$ & \multirow[t]{2}{*}{0.71} & \multirow[t]{2}{*}{0.47} & $29.4(8.3)$ & \multirow[t]{2}{*}{2.6} & \multirow[t]{2}{*}{0.01} \\
\hline Married & $32.5(14.5)$ & & & $12.6(7)$ & & & $34.2(4.1)$ & & \\
\hline Having children & & & & & & & & & \\
\hline Yes & $33(15.2)$ & 0.54 & 0.58 & $12.6(7.4)$ & 0.62 & 0.53 & $34(4.3)$ & 1.9 & 0.057 \\
\hline No & $35.1(10.1)$ & & & $13.8(4.4)$ & & & $30.4(8)$ & & \\
\hline $\begin{array}{l}\text { Regular Physical } \\
\text { Activity/ hobby }\end{array}$ & & & & & & & & & \\
\hline Yes & $30.6(10.4)$ & 0.96 & 0.34 & $12.7(5.8)$ & 0.26 & 0.79 & $34.3(4.5)$ & 1.16 & 0.25 \\
\hline No & $35(13.7)$ & & & $13.3(6.4)$ & & & $31.8(6.8)$ & & \\
\hline $\begin{array}{l}\text { Consider vacation } \\
\text { sufficient }\end{array}$ & & & & & & & & & \\
\hline Yes & $32.5(9.5)$ & 0.52 & 0.6 & $12.1(8)$ & 0.69 & 0.49 & $35.8(3.6)$ & 2.23 & 0.03 \\
\hline No & $34.5(14.1)$ & & & $13.5(5.5)$ & & & $31.2(6.7)$ & & \\
\hline $\begin{array}{l}\text { Years of experience } \\
\text { oncology field }\end{array}$ & & & & & & & & & \\
\hline$\leq 10$ years & $33.9(9.6)$ & 0.009 & 0.99 & $14.2(4.5)$ & 1.5 & 0.13 & $30.7(6.9)$ & 2.33 & 0.02 \\
\hline$>10$ years & $34(17.6)$ & & & $11.4(8.1)$ & & & $35.0(4.5)$ & & \\
\hline $\begin{array}{l}\text { Currently studying } \\
\text { medical degree }\end{array}$ & & & & & & & & & \\
\hline Yes & $32.9(9.4)$ & 0.85 & 0.39 & $13.4(5.7)$ & 0.47 & 0.63 & $32(6)$ & 0.69 & 0.49 \\
\hline No & $36.6(19.9)$ & & & $12.5(7.7)$ & & & $33.4(7.4)$ & & \\
\hline Working hours per & & & & & & & & & \\
\hline$\leq 48$ hours & $34.6(15.2)$ & 0.39 & 0.69 & $12.8(7.4)$ & 0.34 & 0.73 & $32.7(5.7)$ & 0.33 & 0.74 \\
\hline$>48$ houts & $33.1(10.1)$ & & & $13.5(4.5)$ & & & $32(7.3)$ & & \\
\hline $\begin{array}{l}\text { Number of patients } \\
\text { examined per day }\end{array}$ & & & & & & & & & \\
\hline$\leq 15$ patients & $32.3(10.8)$ & 0.88 & 0.38 & $13.8(6.1)$ & 0.7 & 0.48 & $32.6(6.2)$ & 0.25 & 0.79 \\
\hline$>15$ patients & $35.6(14.9)$ & & & $12.5(6.4)$ & & & $32.2(6.7)$ & & \\
\hline Working night shif & & & & & & & & & \\
\hline Yes & $33.2(10.5)$ & 0.25 & 0.79 & $14.9(4.4)$ & 1.26 & 0.21 & $30.6(5.5)$ & 1.23 & 0.22 \\
\hline No & $34.3(14.1)$ & & & $12.4(6.7)$ & & & $33.1(6.7)$ & & \\
\hline $\begin{array}{l}\text { Would choose onco } \\
\text { as career again }\end{array}$ & & & & & & & & & \\
\hline Yes & $30(9.5)$ & 3.56 & 0.001 & $12(5.4)$ & 1.98 & 0.05 & $33.7(5.7)$ & 2.32 & 0.02 \\
\hline No & $43.2(15.7)$ & & & $15.8(7.3)$ & & & $29.2(6.9)$ & & \\
\hline
\end{tabular}

\section{DISCUSSION}

Due to the many stressors faced by oncologists, they may develop burnout. This may be in the form of high levels of EE and DP and reduction in perceived PA ${ }^{1}$.

Compared to other similar studies ${ }^{12-14}$, the response rate in the current study is very high. The vast majority $(>90 \%)$ of invited oncologists completed the questionnaire. This indicates the relevance of the subject to Egyptian oncologists and encourages conducting future research to study the psychological burden among them.

In the current study, and according to MBI definition, $72.3 \%$ suffered from high burnout on the EE scale, $48.9 \%$ on the DP scale and $38.3 \%$ on the PA scale compared to $51.2 \%, 31.8 \%$ and $6.8 \%$ respectively in a Belgian study ${ }^{15}$. In a Turkish study the percentage of high burnout on the EE, DP and PA scales of the MBI was $42 \%, 20 \%$, and $35.6 \%$, respectively ${ }^{16}$. 
This is congruent with the results of a meta-analysis in which burnout was highly prevalent among cancer care professionals around the world ${ }^{17}$. The burnout prevalence in our study was even higher.

Our findings support the concern that oncologists working at Ain Shams Clinical Oncology Department experience high level of stress, examine large number of patients per day and consider vacation time as insufficient. This is the same for many oncologists worldwide ${ }^{12,13}$. Despite all these, the majority of them (70\%) still would select oncology as a career if they had the chance to choose again.

The need for sufficient vacation time was demonstrated in our study, as $74.5 \%$ reported that vacation time was not sufficient. In another study, sufficient vacation time was rated by the majority of medical oncologists as the most important factor to avert burnout ${ }^{12}$. Those who viewed vacation as insufficient lacked personal accomplishment compared to those who viewed it as sufficient and had higher level of burnout on PA subscale.

In a Canadian study that included oncologists working in Ontario, EE was associated with the willingness to change career or reducing hours of work 13. Similarly, in the current study, EE was only significantly higher in oncologists who would not choose oncology as a career again.

The correlation between socio-demographic factors and burnout level has been demonstrated. Age is among these factors and this may be explained by the more difficulties faced during earlier career years. Several studies showed that younger physicians experience higher burnout 16-18. Younger oncologist in our institution didn't show higher levels of burnout. This could be attributed to the fact that the cut-off age for youth in our study was 40 years. Another explanation is that by having more experience and obtaining the master and doctorate degrees, oncologist would handle more patients.

The relation between gender and burnout is inconsistent across studies. Many of the studies found no significant relation while some found that female gender is associated with higher burnout scores ${ }^{16}$. On the other hand, Maslach et al reported higher DP scores among males ${ }^{1}$. Similarly, male oncologists had higher scores on the DP scores which did not reach statistical significance. This may be attributed to the small sample size. In our analysis, females had significantly higher burnout scores on the PA subscale only.

Being married and having children was found to be protective against burnout among oncologists 14, 16, 18-20. Similarly in our study the mean PA score was significantly lower in association with single marital status. Also having children was associated with statistically insignificant lower level of burnout on the PA scale. This was not noticeable on the EE and DP subscales.

Targeting modifiable factors that may contribute to burnout, like insufficient vacation time and high work load may help in reducing burnout among oncologists.

\section{Conclusion}

The surveyed oncologists experienced high burnout level.

Larger studies are needed in order to assess the burden of the problem and to develop evidence-based interventions to reduce it in order to improve the health care outcome in the field of Oncology.

\section{Acknowledgement}

The abstract of this research was accepted for poster presentation at the European Cancer Congress 2015 (18th ECCO - 40th ESMO), 25-29 September 2015, Vienna, Austria. The published abstract citation is: Alorabi M, Ghali R, Boulos D. 1546 Cross-sectional study of burnout among a group of Egyptian oncologists at Ain Shams University. Eur J Cancer. 2015, 51 (Suppl 3): S219-S220. DOI: https://doi.org/10.1016/S0959-8049(16)30636-0

\section{REFERENCES}

1. Maslach C, Schaufeli WB, Leiter MP. Job burnout. Annu Rev Psychol. 2001; 52: 397-422.

2. Dyrbye LN, Thomas MR, Massie FS, et al. Burnout and suicidal ideation among US medical students. Ann Intern Med. 2008; 149(5): 334-341.

3. Shanafelt TD, Bradley KA, Wipf JE, Back AL. Burnout and self-reported patient care in an internal medicine residency program. Ann Intern Med. 2002; 136(5): 358-367.

4. Prins JT, Gazendam-Donofrio SM, Tubben BJ, van der Heijden FM, van de Wiel HB, Hoekstra-Weebers JE. Burnout in medical residents: a review. Med Educ. 2007; 41(8): 788-800.

5. Shanafelt T, Dyrbye L. Oncologist burnout: causes, consequences, and responses. J Clin Oncol. 2012; 30(11): 1235-1241.

6. Ramirez AJ, Graham J, Richards MA, et al. Burnout and psychiatric disorder among cancer clinicians. Br J Cancer. 1995; 71(6): 1263-1269.

7. Shanafelt T, Adjei A, Meyskens FL. When your favorite patient relapses: physician grief and well-being in the practice of oncology. J Clin Oncol. 2003; 21(13): 2616-2619.

8. Lyckholm L. Dealing with stress, burnout, and grief in the practice of oncology. Lancet Oncol. 2001; 2(12): 750-755.

9. Sherman AC, Edwards D, Simonton S, Mehta P. Caregiver stress and burnout in an oncology unit. Palliat Support Care. 2006; 4(1): 65-80.

10. Najjar N, Davis LW, Beck-Coon K, Carney Doebbeling C.Compassion fatigue: A review of the research to date and relevance to cancer-care providers. Journal of Health Psychology. 2009; 14(2): 267-277.

11. Maslach C, Jackson SE, Leiter MP. Maslach burnout inventory manual. Palo Alto (CA): Consulting Psychologists Press; 1996.

12. Whippen DA, Canellos GP. Burnout syndrome in the practice of oncology: results of a random of 1,000 oncologists. J Clin Oncol. 1991; 9(10): 1916-1920.

13. Grunfeld E, Whelan TJ, Zitzelsberger L, Willan AR, Montesanto B, Evans WK. Cancer care workers in Ontario: prevalence of burnout, job stress and job satisfaction. CMAJ. 2000; 163(2): 166-169. 
14. Glasberg J, Horiuti L, Novais MA, et al. Prevalence of the burnout syndrome among Brazilian medical oncologists. Revi Assoc Med Bras (1992). 2007; 53(1): 85-89.

15. Eelen S, Bauwens S, Baillon C, Distelmans W, Jacobs E, Verzelen A. The prevalence of burnout among oncology professionals: oncologists are at risk of developing burnout. Psychooncology. 2014; 23(12): 1415-1422.

16. Demirci S, Yildirim YK, Ozsaran Z, Uslu R, Yalman D, Aras AB. Evaluation of burnout syndrome in oncology employees. Med Oncol. 2010; 27(3): 968-974.

17. Trufelli DC, Bensi CG, Garcia JB, et al. Burnout in cancer professionals: a systematic review and meta-analysis. Eur J Cancer Care (Engl). 2008; 17(6): 524-531.
18. Alacacioglu A, Yavuzsen T, Dirioz M, Oztop I, Yilmaz U. Burnout in nurses and physicians working at an oncology department. Psychooncology. 2009; 18(5): 543-548.

19. Kuerer HM, Eberlein TJ, Pollock RE, et al. Career satisfaction, practice patterns and burnout among surgical oncologists: report on the quality of life of members of the Society of Surgical Oncology. Ann Surg Oncol. 2007; 14(11): 3043-3053.

20. Liakopoulou M, Panaretaki I, Papadakis V, et al. Burnout, staff support, and coping in Pediatric Oncology. Support Care Cancer. 2008; 16(2): 143-150. 